\title{
Acknowledging Diversity: Need of Hour in Education
}

\author{
Neha Yadav \\ Research Scholar, Department of Education, University of Delhi,New Delhi, India \\ Email ID : nhydv@gmail.com
}

Article History: Received: 10 November 2020; Revised 12 January 2021 Accepted: 27 January 2021; Published online: 5 April 2021

\begin{abstract}
Diversity entails differences among individuals in terms of their religion, caste, language, region, culture, traditions, customs, etc. India being a pluralistic society these differences are evident amongst learners in classrooms as well. The need of the hour is to acknowledge this diversity amongst learners in our classrooms and appreciate the heterogeneous pool present in our classrooms. This would help to make the instruction specific to the individual needs of the students resulting in a boost to the educational outcomes of the students concerned
\end{abstract}

Keywords: diversity, education, learners, instruction, heterogenous classroom

\section{Introduction}

India being a pluralistic country houses different types of religions, castes, cultures, traditions languages, etc. However, this diversity can also be seen on the level of school as well amongst our learners. Given the pattern of today's world with increasing migration into the cities has made this diversity even more prominent, now the schools of our country getting more heterogeneous day by day. Having a diverse group of students means recognizing the distinctive quality of every learner in a classroom. The differences could be in terms of learning style, level of skills, cultural background, physical ability, gender, caste, region, language. Diverse learners can also be different in terms of different types of deprivation they are suffering from. The two types of deprivation can be children with disabilities of different kinds including learning difficulties. It gets difficult for the teacher to understand their needs and what s/he can do to make learning possible for them. The others are children belonging to socially and economically deprived backgrounds who are often subjected to social exclusion. This group consists of students belonging to scheduled caste, scheduled tribe, minority community, girls etc. In India, the male literacy rate is 84.7 per cent compared to 70.3 per cent among women [1]. Though the literacy percentage among the scheduled caste and scheduled tribe have taken rapid strides, it is still much lower than the general category students. It is imperative not only to recognize these individual needs but also respect them and model their attitude towards the students based on these. Teachers are confident to claim that they are non-discriminating towards children and they treat all children equally. In cases where there is social differentiation among children, treating each child equally simple means not recognizing, and insensitive to the differential learning needs of the children [2].

\section{Diverse Learners and their special needs}

\section{A. Differences owing to Gender}

Teachers might feel that they treat every student equally and do not differentiate between males and females in a classroom. But the need of every individual whether a girl or a boy can be different. Both have different educative experiences in classrooms. A study concluded that girls don't like lectures, worksheets and assignments, and they prefer to study topics that they perceive as relevant to their lives. Girls are often assigned passive roles in the class and in performance-based assessments. While doing practicals boys complete the tasks using the equipment while girls just read out the instructions and record the results [3]. Teachers may be ignoring the gender biases towards their students which are unconsciously present in them. Teachers' gendered perceptions of students' ability are often seen in the type of praise and expectations they have for their students. Another study observed that teachers give less meaningful praise to girls than boys. The work done by the boys is often described brilliantly while the work done by the girls is undervalued or praised for its appearance. This aspect of teachers' behaviour is particularly detrimental as girls do not receive feedback on their work that could help them develop a greater understanding of concepts [4]. Therefore even gender plays a significant role in making students in a classroom different from each other. 


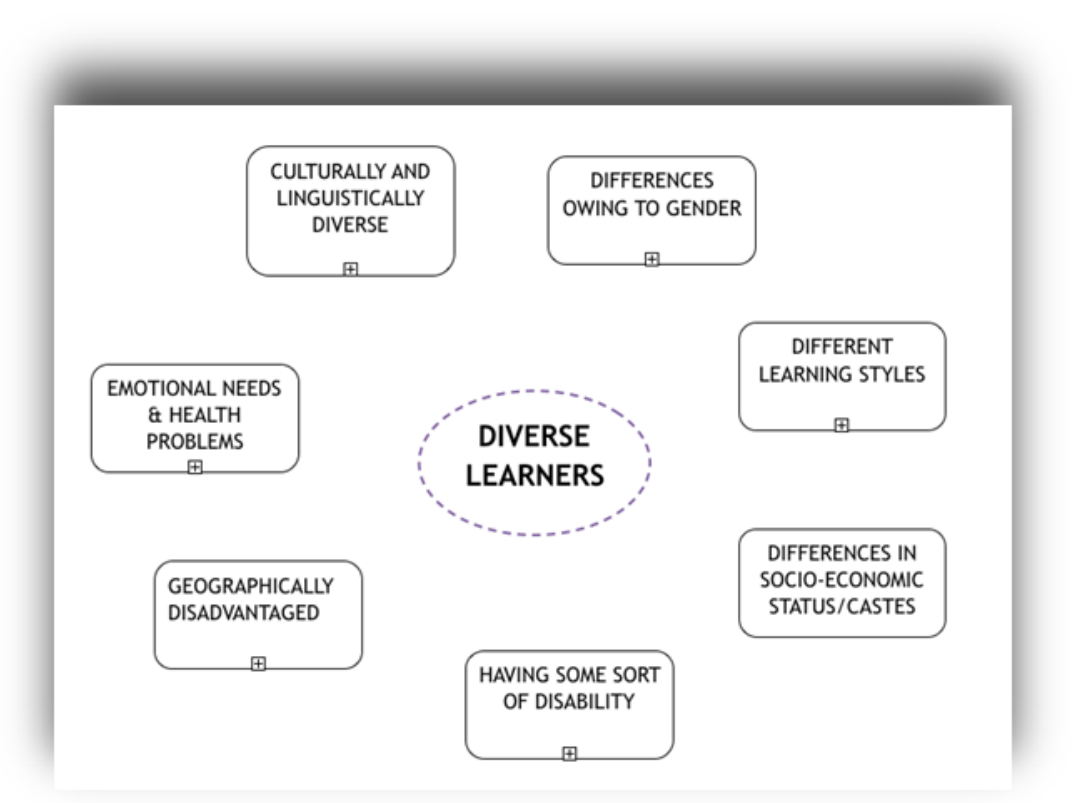

Fig 1:Some examples of diverse learners

\section{B. Students with different learning styles}

Learning style entails how people acquire new information. These learning preferences are associated with the senses that a learner uses while learning. Students use different perceptual strengths when learning [5] which can be auditory (hearing), visual, or kinesthetic (active) in nature as shown below in the table.

TABLE 1: Different Types Of Learning Styles And The Corresponding Student Learning Preferences And Effective Teaching Practices

\begin{tabular}{|l|l|l|}
\hline Learning style & Learning Preferences & Teaching Example \\
\hline Auditory & Listening, talking & Explain things clearly, give verbal examples \\
\hline Visual & $\begin{array}{l}\text { Focusing on handouts and } \\
\text { illustrations }\end{array}$ & $\begin{array}{c}\text { Use the overhead projector and handouts with } \\
\text { charts and graphs }\end{array}$ \\
\hline Active (Kinesthetic) & $\begin{array}{l}\text { Taking notes and interactive } \\
\text { projects }\end{array}$ & $\begin{array}{c}\text { Give hands on creation assignments, allow the } \\
\text { tudent to interact in different activity centers in } \\
\text { the classroom }\end{array}$ \\
\hline
\end{tabular}

(Reprinted From: Terry N.P, Irving M.A,Cultural and linguistic diversity: Issues in education, Special Education for All Teachers. Dubuque, IA: Kendall Hunt, 109-132)

A student may have differential learning preferences and teachers should be aware of this. A teacher should make changes in their lesson plans accordingly and should strive to deliver instruction in a way that incorporates a variety of learning styles or preferences which may include learning by doing, taking the time to explain things clearly, and using charts or handouts. To meet the needs of all students it is important to understand that every student process information differently or may have different strategies for solving problems. By becoming sensitive to the diverse learning styles of the students, can be more effective in generating positive educational outcomes for all students.

\section{Culturally and Linguistically Diverse Students}

Many studies concurthat students from culturally and linguistically diverse backgrounds show poorer educational outcomes than their peers [6]. The cultural norms that dictate interactions amongst students in a classroom are mainly those of the majority cultural or linguistic group present. What is important here is to understand that a child who is linguistically or culturally diverse have their own set of norms, values which they bring inside the classroom which many times might be different from the school norms. Teachers however should resolve this conflict and help the students embrace peer culture. Teachers should understand the need for a culturally and linguistically diverse students and take an interest in who students are, where they come from, and what their perspective is. Often the members of a marginalized racial group, who have a different first language 
labelled as disadvantaged or underprivileged. Historically, such a perspective have been referred to as the deficit model [7]. The deficit model is a perspective that characterizes culturally and linguistically diverse students with a series of negative attributes (e.g., lazy, illiterate, rebellious, violent, and anti-intellectual). Deficit theories blame the victim, promote stereotypes, and neglect them creating a case for educational underachievement. Making use of the unique experiences of the students' culture, teachers can utilise this knowledge of students' background, interests, and experiences to develop culturally relevant pedagogy. Culturally relevant pedagogy is an instructional method and theoretical practice that reinforces students' cultural identity, advances students' achievement, and helps students to develop a critical perspective to challenge the inequities in schools and society [8].

\section{Geographically disadvantage}

A geographically disadvantaged child would be the one who studies in a school in a region which is new to him. New place, new people may create a lot of problems for the child in adjusting to the new environment. In cases where the parentsof the childrenhave a transferable job, these children might find themselves time and again in a new area. These conditions can often be devastating for the child as he is forced to leave his old place, school, teachers, pals etc. In such a scenario it becomes imperative for the teacher to cater to not just academic needs but other needs as well. The teacher can help such students by providing them emotional support, talking to other teachers, helping them to build up good relations with the peers, giving opportunities to speak up in the classroom, encouraging the child etc.

\section{E. Emotional and Health Problems}

If a child is having some emotional problems they might lose interest in the classroom and emotional stress may impact their learning too. One study found the relationship between emotional dispositions and academic performance of middle school students. It showed that emotional regulation is significantly responsible for gradepoint averages of students, apart from the contribution made by their cognition-related abilities [9]. Other than performance issues emotional disturbance can cause many other problems for a child as well such as poor adjustment with peers, feeling of dejection, lack of concentration etc. Students with recurrent feelings of internalized distress (sorrow, anxiety, depression) exhibitreduced academic functioning and those with externalized distress (e.g., anger, disappointment, and dread) showcase difficulties such as delays in learning and subsequently poor achievement [10].

The same thing applies to health also. Poor health hampers educational advancement as studentshaving health problems are not prepared to fully engage or reap benefits of learning opportunities at school or at home [11]. Health thus has a huge impact on a child's learning and engagement in a classroom. Therefore there needs to be an awarenessabout these factors before reaching to any conclusion about the child's academic learning problems and accordingly deal with their children in the classroom.

\section{F. Socio-Economic Status}

A child belonging to a low socio-economic status can have special needs. For instance, it may be possible that children belonging to a poor family have to assist their parents in procuring income for the family. Girls might also be helping their mothers in the household chores. These conditions might have a huge impact on a child's achievement or classroom participation. The teacher thus needs to be aware of the social background and house conditions of the student and treat them accordingly. Teachers' biases in favour of middle-class students and the focusof the school on academic and nonacademic tracking are two main reasons for inequalities in student achievement within schools. The effects of school context can dwarf the effects of family background [12].Sometimes it is also seen that the children may be forced to form their own groups which alienate them from the rest of the class. Hence a teacher should keep in mind the specific needs of a child if $\mathrm{h} / \mathrm{she}$ belongs to a low socio-economic background as it can greatly influence their learning inside a classroom.

\section{G. Disability}

According to the World Health Organisation,disability is a holistic term inclusive of impairments, activity limitations, and participation restrictions. Disability can be defined in terms of functional limitations (limitations of the person based on their functioning and can include occupational capacity), Medical (emphasizes on the classification of a person according to objective indicators of health-related problems), Socio-political (entails the failure of the environment to adapt to the person with a disability). The emphasis is shifted from person to the surroundings [13].

\section{Shifting models of disability: historical progression}

With changing time our perspectives of viewing disability have also changed. Various models talk about the different kinds of definition of disability that have prevailed from the past until the present. Models are influenced by two fundamental philosophies. One sees the disabled people as dependent upon society resulting in segregation and discrimination of disabled people. The other perceives disabled people as recipients of what society has to 
offer. This leads to equality of human rights, and empowerment. Various models viewing disability from different angles are:

The Charity Model- In this disabled people are taken to be victims of circumstances who deserve sympathy.

The Bio-centric Model/ medical model- This understands disability as a physical or mental impairment of the individual and its personal and social consequences. It stresses that the limitations faced by people with disabilities are a result of their own impairments.

The Functional Model- This understands disability as the extent to which a person can pursue his rights independently. Ex. If a disabled child can go to school or not depends on the capacity of the child to access it.

The Human Rights Model- It affirms that all individuals have certain rights which cannot be taken away from them. It works on the principles of accepting diversity, breaking down barriers, non discrimination, equality, reasonable accommodation, access etc. Hence in this, the onus lies on the society to make itself disable friendly rather than the individual.

From the earliest model where the individual was the centre of the focus to the latest model focus has been shifted to society. A teacher being that part of the society can directly influence a child's learning and thus an important instrument of social change. In a classroom teacher works closely with the students and therefore even little changes in their teaching can bring about a significant amount of improvement in the learning and performance of a disabled child. As disability includes specific impairments and limited participation depending on the type of disability, the teacher must cater to these specific needs of a disabled child along with special educators present in most of the schools.

\section{Role of teachers in addressing diversity}

It is important for a teacher to be aware of the socio-economic and family background of students to understand non-academic factors that influence learning. Many factors that affect learning can not be immediately changed, but an understanding of these factors will enable teachers to see student's failure in a different perspective and create a learning environment conducive for the learning. Therefore while addressing classroom teachers should keep in mind that the social and educational profile of the classroom is heterogeneously composed. This implies that the pedagogy should be as per the personal needs, individual learning styles and environmental consequences they are in [14]. Teaching for diversity would mean providing manifold learning activities so that students with different learning styles and abilities have an equal chance of participation $\&$ could succeed. It also means lowering standards or expectations for student performance if needed. Hence some students may need different, or additional, kinds of support to meet high expectations. Knowledge of recognizing is also essential as it is the first step towards inclusion. 'Inclusion means full inclusion of children with diverse abilities with all aspects of schooling that able to access \& enjoy. It involves regular school \& classroom genuinely adapting \& changing to meet the needs of all children as well as celebrating \& valuing differences" [15]. Inclusion is aimed at preparing our school system to meet the needs of all children. The major issue in inclusion is the acceptance of diversity. Inclusive education encompasses the needs of a diverse range of learners and adapting itself to meet these needs. "Inclusion is thus seen as a process of addressing and responding to the diversity of needs of all children, youth and through increasing participation in learning, cultures and communities, and reducing and eliminating exclusion within and from education. It involves changes and modifications in content, approaches, structures and strategies, with a common vision that covers all children of the appropriate age range and a conviction that it is the responsibility of the regular system to educate all children" (UNESCO, 2009, p.8). It aims at all stakeholders in the system (learners, parents, community, teachers, and administrators, policy makers) to be comfortable with diversity and see it as a challenge rather than a problem [14].

\section{Benefits of a diverse classroom}

A diverse classroom has benefits for all the learners, as every child can contribute and bring some unique taste to the learning "soup". Students from diverse backgrounds come to school with already-constructed knowledge acquired in their home and community environments. Not even a single child comes to school without any priorlearning. It is the responsibility of the teacher to set up the framework for constructing new knowledge and understanding based on what the child already knows and what skills he or she already has. Two longitudinal studies conducted at University of Michigan showed that students who had informal interactions with racially and ethnically diverse peers, as well as formal ones within classroom, showed the greatest intellectual engagement, motivation and growth in intellectual \& academic skills [16]. A diverse classroom also gives opportunities to all the students to learn from other students. It gives even greater opportunities to students with disabilities to learn socially appropriate behaviours by interacting with their peers without disabilities. A diverse classroom preparesthe student with and without disabilities for the real world by acknowledging the diversity in the outside world as well. It even helps all the students to develop cross-cultural competence [17]. 


\section{General problems in a diverse classroom}

Although there are several benefits of acknowledging diverse learners in a classroom there are many challenges that can arise in a classroom due to the presence of diverse learners [18]. Some of these are discussed below:

Ineffective Learning- Every child comes from a different family or environment. This might be a hindrance for the teachers in reaching to the students eventually resulting in ineffective learning. It is obviously difficult for the teacher to know about each student, it is important for teachers to monitor and cater to their needs in a variety of ways to achieve effective teaching.

Homogenous materials- Students may react to the textbook differently due to their individual differences. It can be easy/ boring/ hard/ interesting depending on the individual student. Therefore, the teacher needs to evaluate and adapt the materials according to his/her class.

Unequal participation- Some students find it difficult to speak up in the class due to interest/confidence/age/knowledge etc. On the other hand some students are very expressive. As a result, some students require more chances than others to speak.

Indiscipline - Some students are quick to accomplish the task given in the class than others and start disrupting the class. It could also be due to lack of interest of some students in the class. Hence a mixed ability poses a problem for classroom management.

Lack of attention -Some students are quick to lose focus in the class and they don't want to continue studying in the class.

\section{Conclusion}

Every child in a classroom is unique and has a special need. A teacher needs to play a very important role in acknowledging diversity amongst learners to be able to cater to the needs of all the learners. Also, teachers' beliefs about any thing are important for other aspects of education like curriculum development, assessment, etc as well. "Teachers' beliefs and perceptions about their students, their abilities, knowledge and potentialities are critical to teaching and learning that occurs in a particular context. They have a crucial impact on how they develop the curriculum, formulate questions, what they are willing to try differently and more innovatively and how they deliver the curriculum (pedagogy)"(UNICEF Report On Inclusive Classroom, Social Inclusion/Exclusion and Diversity: Perspectives, Policies and Practices, 2010, p59). Therefore one needs to understand that diversity is an asset, not a liability and acknowledging this diversity current need of the hour in education

\section{References}

Report based on National Sample Survey Office survey (2018) Government Of India.

Singh, P. D. and Kumar, Sanjay (2010). Social Hierarchy and Notion of Educability: Experiences of Teachers and Children From Marginalized and Non-Marginalized Communities, Dalit Studies Series, No. 3, New Delhi: Deshkal

Scantlebury, K., \& Baker, B. (2007). Gender issues in science education research: Remembering where the difference lies. In S.K. Abell \&amp; N.G. Lederman (Eds.), Handbook of research on science education (pp. 257-285). Mahwah, NJ: Erlbaum.

Liu, F. (2006). School culture and gender. In C. Skelton, B. Francis, \&amp; L. Smulyan (Eds.), The SAGE Handbook of Gender and Education (pp. 425-438). Thousand Oaks, CA: Sage.

Kolb, D.A. (1984). Experiential learning: Experience as the source of learning and development. Englewood Cliffs, NJ: Prentice Hall.

Conchas, G.Q. \& Noguera, P.A. (2004). Understanding the exceptions: How small schools support the achievement of academically successful black boys. In N. Way \& amp; J.Y. Chu (Eds.), Adolescent boys: Exploring diverse cultures of boyhood. (pp. 317-337). New York: New York University Press.

Solorzano, D.G., \& Yosso, T.J. (2001). From racial stereotyping and deficit discourse toward a critical race theory in teacher education. Multicultural Education, 9(1), 2-8.

Ladson-Billings, G. (1995). Toward a theory of culturally relevant pedagogy. American Educational Research Journal, 32(3), 465-491.

Gumora, G., \& Arsenio, W. F. (2002). Emotionality, emotion regulation, and school performance in middle school children. Journal of School Psychology, 40, 395-413.

Roeser, R. W., Eccles, J. S., \& Strobel, K. R. (1998). Linking the study of schooling and mental health: Selected issues and empirical illustrations at the level of the individual. Educational Psychologist, 33, 153-176.

Hanson, T. L., Austin, G., \& Lee-Bayha, J. (2004). Ensuring that no child is left behind: How are student health risks and resilience related to the academic progress of schools? San Francisco, CA: WestEd 
Borman, Geoffrey \& Dowling, N. Maritza. (2010). Schools and Inequality: A Multilevel Analysis of Coleman's Equality of Educational Opportunity Data. Teachers College Record. 112. 1201-1246.

Bernell, S. L. (2003). Theoretical and applied issues in defining disability in labor market research. Journal of Disability Policy Studies, 14(1):36-45.

Towards Inclusive Education (2010) State Council of Educational Research and Training Manual For General Teachers: New Delhi.

Loreman, T., Deppeler, J. M., \& Harvey, D. H. P. (2005). Inclusive education: A practical guide to supporting diversity in the classroom. Sydney: Allen and Unwin.

Gurin, P., Dey, E.L., Hurtado, S., \& Gurin, G. (2002). Diversity and Higher Education: Theory and Impact on Educational Outcomes. Harvard Educational Review, 72, 330-367.

Voltz D. L., Sims, M. J. and Nelson, B. (2010). Connecting Teachers, Students, and Standards: Strategies for Success in Diverse and Inclusive Classrooms. Alexandria, VA: Association for Supervision and Curriculum Development.

Naryanan R. (2009). How to Work Effectively with a Heterogeneous Classroom In Humanising language teaching. 11(5), ISSN 1755-9715: UK Pilgrims Language Courses. 